\title{
Geochemical Properties and Biochemical Composition of the Surfactant Mixture Surrounding Natural Microbubbles in Aqueous Media
}

\author{
J. S. D'ARRIGO,* C. SAIZ-JIMENEZ † AND N. S. REIMER \\ Department of Applied Mathematics, Institute of Advanced Studies, Australian National University, Canberra, \\ Australian Capital Territory 2600, Australia, and "Department of Physiology, University of Hawaii, Honolulu, \\ Hawaii 96822, +Direccion General de Medio Ambiente, Junta de Andalucia, Avda. Republica Argentina, \\ 21-B Acc., and †Centro de Edafologia, CSIC, Apartado 1052, Sevilla, Spain, and $\ddagger$ Department of \\ Biochemistry and Biophysics, University of Hawaii, Honolulu, Hawaii 96822
}

Received September 20, 1983; accepted December 23, 1983

\begin{abstract}
A water-soluble extract from a Hawaiian forest soil, rich in biological surfactants, has been chemically characterized by elemental, infrared, and X-ray diffraction analyses and by pyrolysis mass spectrometry. A probable interaction of these rather hydrophobic surfactants with abundant minerals in the Hawaiian soil extract is suggested. Such interactions between oxygen groups and metal ions may aid in the dispersal of the surfactants in natural waters. These biological surfactants, which were previously shown to stabilize long-lived gas microbubbles in aqueous media, were then isolated, purified, and their heterogeneity examined using a variety of biochemical methods. It is concluded that microbubble surfactant actually represents a glycopeptide-lipopolysaccharide complex, which is reversibly held together by both hydrogen bonding and nonpolar interactions. Additional data are given which suggest that the glycopeptide fraction is probably derived from the main chlorophyll-protein complex present in higher plants and green algae.
\end{abstract}

\section{INTRODUCTION}

Many natural waters and water extracts from soils often exhibit a yellowish to brown color owing to the presence of organic substances. The color in natural waters, according to Christman and Ghassemi (1), originates from the decay of the forest vegetation. A detailed knowledge of the chemistry of these organic substances is needed to adequately account for the important properties of naturally occurring surfactants often found in forest soil (2). The importance of these biological surfactants stems from the ability of some of them to stabilize gas microbubbles in both fresh and sea water over long periods of time (2-5). The presence of such stable gas microbubbles in natural waters is of practical concern to fields as varied as fisheries research, ocean engineering, and commercial oil recovery $(5,6)$. Accordingly, to understand the geochemical properties of the surfactant mixture surrounding natural microbubbles, a water-soluble extract from a Hawaiian forest soil, rich in mi- crobubble surfactants (5), has been chemically characterized in the present study.

A second objective of this investigation was to obtain additional biochemical data on the isolated microbubble surfactant mixture itself. This surfactant mixture was shown in earlier studies to contain low-molecular-weight glycopeptides of similar structure, which were invariably contaminated with a much greater quantity of oligosaccharide material (5). The low solubility in water (5) and oily nature of the microbubble surfactant mixture further suggested that lipids, previously unidentified, might also represent a major component of the mixture. In this paper, we provide data on the biochemical heterogeneity of the microbubble surfactant mixture and identify the probable natural source of its characteristic glycopeptide fraction.

\section{MATERIALS AND METHODS}

Preparation of aqueous soil extract. The $A_{11}$ $+A_{12}$ horizons from a Udorthent soil, rep- 
resentative of the Kokokahi clay series, was used. This was of the montmorillonitic, isohyperthermic family, located at the island of Oahu, Hawaii (7).

Solutions were prepared using $2 \mathrm{~kg}$ of (damp) surface soil added to 10 liters of distilled water and refrigerated. The mixture was gently swirled at intervals for 1 day, and all undissolved materials were allowed to settle on the second day. The supernatant was filtered with suction through a precleaned Gelman Acropor 3- $\mu \mathrm{m}$ (pore diameter) membrane filter in conjunction with a Gelman thick glass-fiber prefilter. Two-thirds of the resulting filtrate was utilized for isolation of microbubble surfactant (see below), while the remainder was pipetted in $15-\mathrm{ml}$ aliquots into separate glass vials and stored frozen until needed. The $15-\mathrm{ml}$ aliquots were lyophilized to get the dry powder sample for analyses.

Elemental, infrared, and $X$-ray diffraction analyses. Elemental analyses were determined by the Canadian Microanalytical Service Ltd., Vancouver. The total $\mathrm{Ca}, \mathrm{Mg}, \mathrm{P}, \mathrm{Na}, \mathrm{K}$, and Fe were determined by Dr. Carmen Mazuelos, Centro de Edafologia, with a Perkin-Elmer Model 703 absorption spectrophotometer. The infrared spectrum of the lyophilized material was taken on $\mathrm{K} \mathrm{Br}$ pellets ( $1 \mathrm{mg}$ sample in $200 \mathrm{mg} \mathrm{K} \mathrm{Br}$ ) with a Perkin-Elmer Model 337 infrared spectrophotometer. X-Ray diffraction analysis was carried out by Dr. Carmen Hermosin, Centro de Edafologia, in a Philips PW 1010 diffractometer using Ni-filtered, $\mathrm{Cu} K \alpha$, radiation operated at $30 \mathrm{kV}$ and $20 \mathrm{~mA}$, scanning speed of $1 \% \mathrm{~min}$, time constant 2 , and range of diffraction angles from 2 to $60^{\circ}$.

Pyrolysis mass spectrometry. The method has been described extensively in previous papers $(8,9)$. The extract $(1 \mathrm{mg})$ was suspended in methanol $(1 \mathrm{ml})$ by mild ultrasonic treatment. From this suspension, $5-\mu l$ samples were applied to ferromagnetic coated wires and the solvent was evaporated under rotation. The coated wires were mounted in glass reaction tubes. The automated pyrolysis mass spectrometry system has been described in detail elsewhere (10). Briefly, it consists of a sample changing device, a Curie-point pyrolysis reactor with a high-frequency generator (Fisher Labortechnik GmbH, $1.5 \mathrm{~kW}, 1.1 \mathrm{MHz}$ ), a quadrupole mass spectrometer (Riber, QM17) with an ion counting detector, and a minicomputer (D-116, Digital Computer Controls). Pyrolysis was accomplished by inductive heating up to the Curie-temperature $\left(510^{\circ} \mathrm{C}\right)$ of the ferromagnetic wire $(\mathrm{Fe} / \mathrm{Ni})$ within 0.1 s. The total heating time was $0.8 \mathrm{sec}$. For normalization and graphic representation, peaks at 43 and $44 \mathrm{~m} / z$ were deleted in the case of the Hawaiian soil extract.

Isolation of microbubble surfactant. Isolation of the microbubble surfactant mixture itself from the aqueous soil extract followed the protein-extraction method used in earlier work (5) on forest soils and also commercial agarose from marine algae. Table I provides a typical example of the effectiveness of the protein-extraction method in removing surfactant-stabilized microbubbles from agarose gels (5), as evidenced by the drastic reduction in bubble production upon decompression of such gels. In the present study, the aqueous soil extract (see above) was diluted with $4 \mathrm{vol}$ of $95 \%$ ethanol, after which a dark-brown precipitate slowly formed. After $24 \mathrm{hr}$, the precipitate was removed by filtration through a precleaned 3- $\mu \mathrm{m}$ membrane filter; the filtrate was then refiltered through a 5000-Da cutoff molecular filter (Nuclepore). This filtrate, which contained the microbubble surfactant, was concentrated over a 1,000-dalton cutoff molecular filter (Nuclepore). The retentate,

TABLE I

Bubble Production following Rapid Decompression to Atmospheric Pressure of Agarose Gels $(0.27 \mathrm{ml})$ Saturated with $\mathrm{N}_{2}$ at 85 psig

\begin{tabular}{ccc}
\hline Gel type & $\begin{array}{c}\text { No. of } \\
\text { trials }\end{array}$ & $\begin{array}{c}\text { No. of bubbles } \\
\text { (mean } \pm \text { SEM) }\end{array}$ \\
\hline $\begin{array}{c}\text { Agarose (Lot 60808) } \\
\text { before protein extraction }\end{array}$ & 12 & $24.67 \pm 2.95$ \\
$\begin{array}{c}\text { Agarose (Lot 60808) after } \\
\text { protein extraction }\end{array}$ & 36 & $0.08 \pm 0.05$ \\
\hline
\end{tabular}

Journal of Colloid and Interface Science, Vol. 100, No. 1, July 1984 
containing concentrated surfactant, was then diluted with high-purity absolute ethanol and reconcentrated. The absolute ethanol wash was repeated three times, leaving a final retentate volume of $22 \mathrm{ml}$ (containing approximately $550 \mu \mathrm{g}$ of protein). Half of this volume was employed in a concurrent monolayer study (11), while the other half was concentrated by evaporation in preparation for column chromatography.

Gel-filtration column chromatography, amino acid analysis, and carbohydrate determination. The concentrated microbubble surfactant sample $(1.0 \mathrm{ml})$ was applied directly to a column $(1.5 \mathrm{~cm}$ i.d. $\times 35 \mathrm{~cm}$ ) of Sephadex LH-20, which had been prewashed with $95 \%$ ethanol over a period of 1 week and thereafter equilibrated with 95\% high-purity ethanol/5\% water. The column was eluted with the equilibrating solvent mixture, at a flow rate of $1 \mathrm{ml} / 4 \mathrm{~min}$. The volume per fraction was $0.65 \mathrm{ml}$, and each fraction was combined with an added $0.7-\mathrm{ml}$ aliquot of the same solvent mixture before being analyzed on a Beckman Model 25 spectrophotometer at 230 and $280 \mathrm{~nm}$.

Selected fractions were pooled and prepared for automated amino acid analysis by (complete) hydrolysis in $5.7 \mathrm{~N} \mathrm{HCl}$ in evacuated, sealed ampules for $24 \mathrm{hr}$ at $110^{\circ} \mathrm{C}$. Analyses were performed on a Beckman $120 \mathrm{C}$ amino acid analyzer.

Other fractions were prepared for carbohydrate analysis by hydrolysis (of the surfactants' glycosidic bonds) in $2 \mathrm{~N} \mathrm{HCl}$ in sealed ampules for $6 \mathrm{hr}$ at $100^{\circ} \mathrm{C}(12)$. Monosaccharide analyses were performed on a programmed Tracor 985 high-performance liquid chromatography (HPLC) system employing a Bio-Rad HPX-87C cation-exchange column for monosaccharide separation.

\section{RESULTS}

Chemical characterization of the soil extract yields, on an ash-free basis, $26.3 \% \mathrm{C}, 4.6 \% \mathrm{H}$, $5.5 \% \mathrm{~N}$, and $63.6 \% \mathrm{O}+\mathrm{S}$ (by difference). Ash content was $37.4 \%$. The ash composition was
$22.0 \% \mathrm{Ca}, 8.0 \% \mathrm{Mg}, 6.25 \% \mathrm{P}, 2.06 \% \mathrm{Na}, 1.51 \%$ $\mathrm{K}$, and $1.75 \% \mathrm{Fe}$.

Although the application of IR spectroscopy to soil organic matter is somewhat limited by the nature of such material which contains numerous infrared active groups that lead to extensive overlapping of individual absorptions, several bands do appear as discrete or reasonably well defined in humic compounds $(13,14)$. For example, in such IR studies, hydrogen bonded $\mathrm{OH}$ groups give a broad absorption band with a maximum around 3400 $\mathrm{cm}^{-1}$, while carboxylate ions $\left(\mathrm{COO}^{-}\right)$display bands at ca. 1620 and $1380 \mathrm{~cm}^{-1}$, all of which are observed in the Hawaiian soil extract (Fig. 1). This spectrum is similar to those reported by Dormaar (15) for lyophilized defrost water obtained during spring thaw from Canadian Black Chernozemic $A_{\mathrm{h}}$ and $A_{\mathrm{p}}$ horizons, in which some of the bands were assigned to nitrates, sulfates, and carbonates. Spectra for pure sulfates (major band at ca. $1100 \mathrm{~cm}^{-1}$ ), nitrates (major bands at ca. 1420 and 1385 $\mathrm{cm}^{-1}$ ), and carbonates (major bands at 1420 and $875 \mathrm{~cm}^{-1}$ ) showed absorption bands in agreement with those found in the Hawaiian soil extract. Both extracts showed that $\mathrm{Ca}$ and $\mathrm{Mg}$ were the main cations. Therefore, bands for organic components were probably masked by the inorganic contribution. The X-ray diffraction pattern, in Ångstroms, was 2.82 (I/ $\left.I_{0}=100\right), 1.99(43)$, and $1.62(12)$. The ASTM data for $\mathrm{NaCl}$ was $2.82(100), 1.99(55)$, and

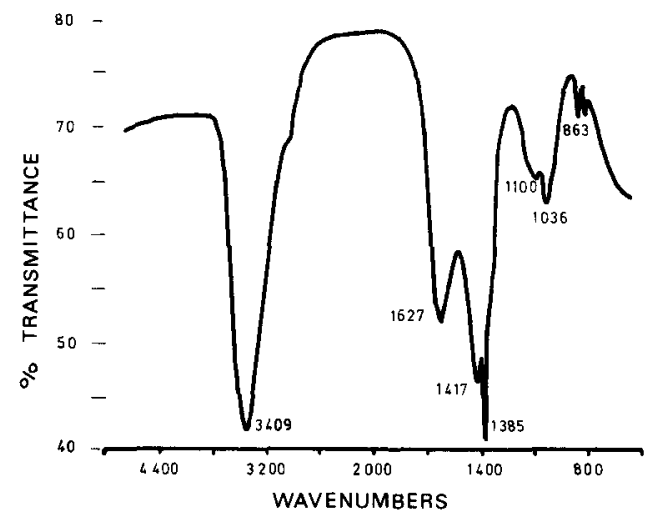

FIG. 1. IR spectrum of the Hawaiian soil extract. 
1.62 (15). Therefore, $\mathrm{NaCl}$ was also present in the soil extract, although it was not evidenced in the infrared spectrum because of the lack of such absorption properties by this compound.

Figure 2A presents the pyrolysis mass spectrum for the soil extract. In previous work (8, $9,16)$ it was shown that complex organic materials like polysaccharides, proteins, lignins, and soil humic fractions have characteristic peaks yielding a typical pattern, which give preliminary information about the composition of the pyrolysis fragments. Thus, char- acteristic peaks for polysaccharides were observed at $60,68,82,84,96,98,110,112$, and $126 \mathrm{~m} / \mathrm{z}$, which were also present in the soil extract. They were shown to be related to acetic acid, furan, methylfuran, hydroxyfuran, furfural, furfuryl alcohol, methylfurfural, methoxymethylfuran, and a typical pyrolysis fragment of polysaccharides with hexose and/ or deoxyhexose units, respectively.

Alkenes were indicated by prominent peaks at $28,42,56,70$, and $84 \mathrm{~m} / z$ (ethene to hexene). They were probably derived from aliphatic acids, as evidenced by the fragment
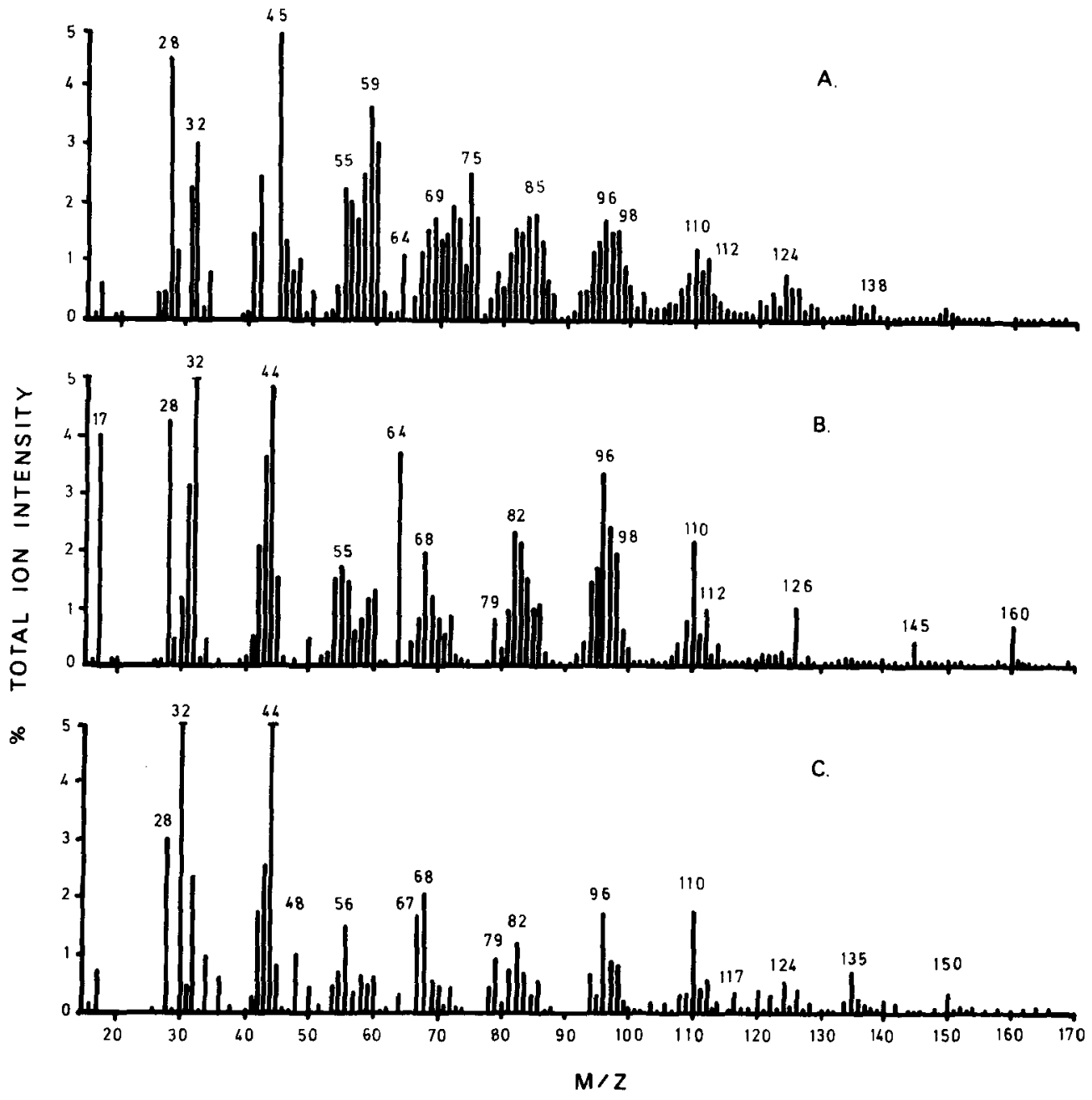

FIG. 2. Pyrolysis mass spectra: (A) Hawaiian soil extract; (B) fulvic acid from Typic Chromoxerert; (C) water-soluble humic acid from Typic Chromoxerert. 
series at $43,57,71,85 \mathrm{~m} / \mathrm{z}$, and a massive peak at $44 \mathrm{~m} / z\left(\mathrm{CO}_{2}\right)$ indicating an extensive decarboxylation. (Note that 43 and $44 \mathrm{~m} / z$ are not shown in Fig. 2A; see Materials and Methods.)

The peaks seen at $67,81,95$, and 117 $m / z$ (Fig. 2A) are common for nitrogen-containing materials (e.g., proteins, peptides, amino acids) and are likely to represent (alkyl) pyrroles and indole. In addition, some peaks were related to aromatic compounds, for example, those at 92 (toluene), 94 (phenol), 108 (cresol), $120\left(\mathrm{C}_{2}\right.$-alkylbenzene and/or vinyl phenol), 122 (xylenol), 124 (guaiacol), and 138 $\mathrm{m} / z$ (methylguaiacol) (Fig. 2A). Guaiacol derivatives are typical pyrolysis products of lignins and lignin degradation products (17). Toluene, phenol, cresol, and xylenol arise from either aromatic amino acids, lignins, or humic substances.

Soil fulvic acid (Fig. 2B) shows dominant signals similar to those observed in a complex polysaccharide spectrum (9), with peaks at 68 , $82,84,96,98,110,112,114,126$, and 128 $\mathrm{m} / z$. In addition, nitrogen-containing fragments are low. Evidence of polysaccharide is also shown in the spectrum of a water-soluble fraction of humic acid (Fig. 2C), isolated by gel filtration (13). However, the presence of homologous ion series of sulfides $(34,48$ $m / z)$, pyrroles $(67,81,95 \mathrm{~m} / z)$, pyridine $(79$ $m / z)$, benzenes $(78,106 \mathrm{~m} / z)$, phenols (94, $108,122 \mathrm{~m} / z)$, indole $(117 \mathrm{~m} / \mathrm{z})$, and ligninderived units $(124,138,150 \mathrm{~m} / \mathrm{z})$ with variable intensity, indicate the similarity with other soil humic fractions (9).

The above-mentioned strong indication of alkenes (derived from acyl lipids) by the pyrolysis mass spectrum of the soil extract accords well with results from iodine-stained, thin-layer chromatography of the isolated microbubble surfactant mixture itself; these biochemical data indicated a high content of unsaturated acyl lipids (Reimer and D'Arrigo, unpublished data). This prominent lipid content, as well as the large proportion of oligosaccharide material, was again noted during concentration of the isolated microbubble surfactant mixture, prior to further purification via column chromatography in this study. During evaporation, a large quantity of whitish precipitate steadily formed. The whitish precipitate was subsequently found to contain carbohydrate and lipid material, the former determined by HPLC and the latter by thinlayer chromatography and nuclear magnetic resonance (NMR) spectroscopy (see also below).

The gel-filtration column chromatography of the concentrated microbubble surfactant mixture, on Sephadex LH-20, resulted in the surfactant mixture being separated into three major peaks (Fig. 3). As in the previous bio-

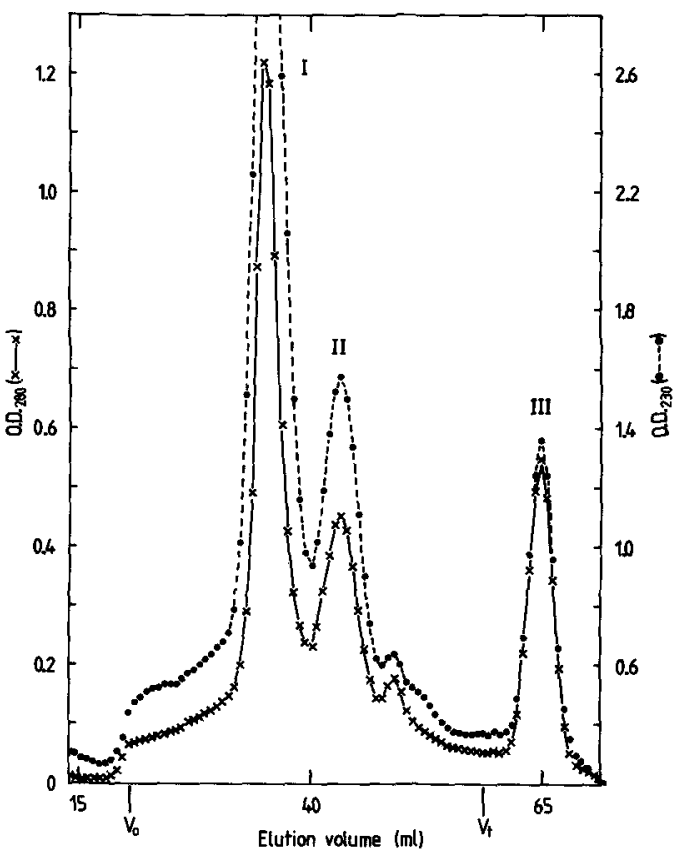

FIG. 3. Gel-filtration column chromatography of partially purified microbubble surfactant using Sephadex LH20. The column $(1.5 \mathrm{~cm}$ i.d. $\times 35 \mathrm{~cm})$ was washed and equilibrated with $95 \%$ ethanol $/ 5 \%$ water over a period of 1 week. The column was eluted with the equilibrating solvent mixture, at a flow rate of $1 \mathrm{ml} / 4 \mathrm{~min}$. The volume per fraction was $0.65 \mathrm{ml}$, and each fraction was combined with an added $0.7 \mathrm{ml}$ aliquot of the same solvent mixture before being analyzed spectrophotometrically at 230 and $280 \mathrm{~nm}$. 
chemical study (5), most of the surfactant material (peaks I and II) eluted soon after the void volume $\left(V_{0}\right)$; hence, the surfactant molecules succeeded in entering the Sephadex LH20 gel matrix, which has an exclusion limit in ethanol of approximately $4000 \mathrm{Da}$ (18). However, there was a higher proportion of late-eluting (and possibly interacting (18)) surfactant material (peak III) from this preparative column chromatography than observed in the previous study. [This result and additional minor differences may well stem from the fact that although the forest soil used in both studies was taken from the same exact physical site, the actual dates of soil collection for the two cases differed by 1.5 years.]

To obtain data on the heterogeneity of the glycopeptide fraction of microbubble surfactant, comparative amino acid analyses were performed on two of the major peaks obtained from gel filtration. From the ratio of absorbances at 230 and $280 \mathrm{~nm}$ (7) and the elution profile shown in Fig. 3, it appeared that peaks I and III would differ the most in amino acid composition and, therefore, these two peaks were selected for amino acid analysis. Peak I was sufficiently large to be divided into three equal aliquots and peak III into two equal aliquots for automated analysis. Peak II, which eluted closest (Fig. 3) to the dominant peak I and presumably was most similar in molecular composition to this large initial peak, was analyzed separately by HPLC for carbohydrate content.

Table II lists the amino acid values obtained from the individual determinations for peaks I and III. Agreement between individual trials was excellent for the dominant peak $I$, and mostly very good for peak III where less proteinaceous material was available for analysis. Judging from the obvious absence of proline in peak III, it may well be the case that the material contained in this late-eluting (Fig. 3) peak, having a total amino acid composition (except for proline) somewhat similar to peak I, represents a partial degradation product (or several products) of the dominant, first peak.
TABLE II

Amino Acid Composition ${ }^{a}$ of Microbubble Surfactant Peaks Obtained from Sephadex LH-20 Chromatography (shown in Fig. 1)

\begin{tabular}{|c|c|c|c|c|c|}
\hline \multirow[b]{2}{*}{ Amino acid } & \multicolumn{3}{|c|}{ Peak I determinations } & \multicolumn{2}{|c|}{$\begin{array}{c}\text { Peak III } \\
\text { determinations }\end{array}$} \\
\hline & 1st & 2nd & 3 rd & Ist & 2 nd \\
\hline Aspartic acid ${ }^{b}$ & 6.69 & 6.63 & 6.71 & 7.74 & 8.20 \\
\hline Threonine & 7.64 & 7.70 & 7.69 & 6.76 & 6.09 \\
\hline Serine & 10.72 & 11.03 & 10.91 & 11.72 & 10.27 \\
\hline Glutamic acid ${ }^{c}$ & 12.99 & 12.74 & 12.70 & 16.72 & 17.68 \\
\hline Proline & 7.38 & 7.17 & 6.91 & 0 & 0 \\
\hline Glycine & 15.53 & 15.80 & 15.25 & 22.17 & 21.59 \\
\hline Alanine & 9.44 & 9.65 & 9.61 & 7.04 & 7.88 \\
\hline Cysteine $^{d}$ & 0 & 0 & 0 & 0 & 0 \\
\hline Valine & 9.71 & 10.03 & 10.01 & 5.69 & 4.94 \\
\hline Methionine & 0 & 0 & 0 & 0 & 0 \\
\hline Isoleucine & 5.31 & 4.74 & 4.90 & 3.14 & 3.30 \\
\hline Leucine & 9.48 & 9.29 & 9.38 & 6.46 & 7.48 \\
\hline Tyrosine & 1.19 & 1.02 & 1.35 & 3.53 & 3.39 \\
\hline Phenylalanine & 2.04 & 1.92 & 2.12 & 2.61 & 2.62 \\
\hline Lysine & 0.93 & 1.30 & 1.32 & 2.05 & 2.11 \\
\hline Histidine & 0 & 0 & 0 & 0 & 0 \\
\hline Arginine & 0.97 & 0.97 & 1.12 & 4.37 & 4.48 \\
\hline
\end{tabular}

Note. Values for individual determinations are given in mole\%.

${ }^{a}$ Hydrolysis in $5.7 \mathrm{~N} \mathrm{HCl}$ for $24 \mathrm{hr}$ at $110^{\circ} \mathrm{C}$. No corrections have been made for destruction (e.g., tryptophan) or incomplete hydrolysis.

${ }^{b}$ Value includes asparagine residues also.

$c$ Value includes glutamine residues also.

${ }^{d}$ Cysteine as $1 / 2$-cystine.

In any case, the very prominent, early peak (I) appears to have been quite homogeneous in its peptide composition, as judged from the excellent agreement of the separate amino acid analyses for this particular peak (Table II). This finding may indicate the existence of a single, but yet widespread, type of glycoprotein precursor for the main glycopeptide subfraction from microbubble surfactant (see Table III and Discussion).

From the carbohydrate analyses of peak II, it was determined that $780 \mu \mathrm{g}$ of polysaccharide (i.e., polymers of neutral monosaccharides with polymer mol wt of 1000-5000) were reversibly complexed with the estimated $19.5 \mu \mathrm{g}$ of gly- 
TABLE III

Amino Acid Composition ${ }^{a}$ of the Main Glycopeptide Subfraction (Peak I in Table II) from Microbubble Surfactant and of the Light-harvesting Chlorophyll $a / b$-Protein from Higher Plants and a Green Alga

\begin{tabular}{|c|c|c|c|c|c|c|c|}
\hline \multirow[b]{2}{*}{ Amino acid } & \multirow[b]{2}{*}{$\begin{array}{l}\text { Peak I } \\
\text { (mean) }\end{array}$} & \multicolumn{6}{|c|}{ Light-harvesting chlorophyll $a / b$-protein } \\
\hline & & $\begin{array}{c}\text { Spinach } \\
\text { beet }^{b}\end{array}$ & Tobacco $^{b}$ & $\mathrm{Oat}^{b}$ & Spinach $^{b}$ & Spinach $^{e}$ & Chlamydomonas ${ }^{d}$ \\
\hline Aspartic acid & 6.7 & 9.5 & 9.4 & 9.8 & 9.7 & 11.0 & 8.8 \\
\hline Threonine & 7.7 & 3.1 & 3.0 & 3.8 & 2.6 & 3.1 & 5.0 \\
\hline Serine & 10.9 & 4.4 & 4.2 & 3.3 & 3.4 & 5.5 & 3.6 \\
\hline Glutamic acid $f$ & 12.8 & 9.4 & 9.1 & 9.6 & 8.9 & 8.8 & 9.1 \\
\hline Proline & 7.2 & 7.4 & 7.8 & 7.0 & 7.9 & 7.9 & 7.2 \\
\hline Glycine & 15.5 & 13.1 & 14.0 & 13.1 & 13.8 & 13.6 & 12.5 \\
\hline Alanine & 9.6 & 10.6 & 11.9 & 11.5 & 10.4 & 10.2 & 11.2 \\
\hline Cysteine $^{g}$ & 0 & 0.5 & - & - & - & - & 0.6 \\
\hline Valine & 9.9 & 6.8 & 6.6 & 7.1 & 7.1 & 6.3 & 4.4 \\
\hline Methionine & 0 & 1.6 & - & - & - & 1.0 & 1.7 \\
\hline Isoleucine & 5.0 & 4.6 & 4.7 & 4.7 & 4.2 & 2.6 & 4.4 \\
\hline Leucine & 9.4 & 10.0 & 10.6 & 10.8 & 11.1 & 10.3 & 11.5 \\
\hline Tyrosine & 1.2 & 2.6 & 2.3 & 2.8 & 2.2 & 2.8 & 3.3 \\
\hline Phenylalanine & 2.0 & 5.8 & 6.7 & 6.3 & 7.2 & 6.4 & 6.8 \\
\hline Lysine & 1.2 & 5.4 & 5.3 & 5.7 & 6.3 & 5.1 & 5.3 \\
\hline Histidine & 0 & 1.1 & 0.9 & 1.0 & 1.4 & 1.4 & 1.5 \\
\hline Arginine & 1.0 & 3.1 & 3.2 & 3.5 & 3.6 & 3.2 & 3.2 \\
\hline Tryptophan & - & 1.1 & - & - & - & 1.0 & - \\
\hline
\end{tabular}

${ }^{a}$ Hydrolysis in $5.7 \mathrm{~N} \mathrm{HCl}$ for $24 \mathrm{hr}$ at $110^{\circ} \mathrm{C}$. No corrections have been made for destruction (e.g., tryptophan) or incomplete hydrolysis. Values for individual determinations are given in mole\%.

${ }^{b}$ Ref. (30).

${ }^{c}$ Ref. (31).

${ }^{d}$ Ref. (32).

${ }^{e}$ Value includes asparagine residues also.

$r$ Value includes glutamine residues also.

${ }^{g}$ Cysteine as 1/2-cystine.

copeptide contained in this peak. Hence, the calculated carbohydrate:glycopeptide weight ratio is approximately $40: 1$.

\section{DISCUSSION}

Aqueous extracts from forest soils contain aliphatic organic acids and phenolic compounds, free or linked to condensed structures (19). It appears that the Hawaiian soil extract also includes these kinds of materials. Aliphatic acids are decarboxylated upon pyrolysis and the soil extract spectrum has peaks which predominate at 43 and $44 \mathrm{~m} / \mathrm{z}\left(\mathrm{CO}_{2}\right)$, which were deleted in order to normalize the spectrum for graphic representation. Furthermore, the carboxyl groups were most probably bonded to the inorganic constituents by forming salts and chelates, explaining the high amount of ash found. Consequently, the ash and its catalytic effects, together with the relative sparsity of condensed structures, cause an extensive fragmentation of the Hawaiian soil extract by pyrolysis (Fig. 2A), in contrast to the soil humic fractions (see Figs. 2B and C) (9).

Polysaccharides probably constitute one of the most abundant fractions in soil organic matter and they are present as such or combined with the extracted humic fractions. As can be seen from the findings with soil extract 
and humic fractions (Results), water-soluble materials are made up of a complex mixture of polysaccharides, proteins, phenolic, and lignin-derived compounds, as well as other aliphatic materials. These compounds are present in various proportions, from which some of the oxygen-containing functional groups (carboxyls, phenolic, and alcoholic hydroxyls, etc.) are capable of interacting with metal ions, metal oxides, metal hydroxides, and more complex minerals to form metalorganic associations of widely differing chemical and biological stabilities and characteristics. In this connection, Dawson et al. (20) pointed out that water-soluble compounds contain strongly chelated carboxylic acid groups playing a major role in the organic matter-metal interaction. Most of the watersoluble materials from forest soils are less than $5000 \mathrm{Da}$, and with them are associated most of the metals (20-22).

Similarly, all of the microbubble surfactants which have been characterized biochemically to date from Hawaiian forest soil are known to be below $5000 \mathrm{Da}$ (Results; (5)). The probable association of these rather hydrophobic (5) microbubble surfactants with the cations found in the Hawaiian soil extract, as suggested by our results and those of Dawson $e t$ al. (20), may well aid in the dispersal of the surfactants in natural waters. Accordingly, this oxygen group-metal interaction increases the ability of the microbubble surfactants to eventually reach the air-water interface of macroscopic bubbles in these waters. The surfactants contained in this water-soluble mixture would be expected to include glycopeptides, oligosaccharides, and acyl lipids, based upon the biochemical data obtained on isolated microbubble surfactant (Results). Therefore, it is logical that the pyrolysis mass spectrum for the Hawaiian soil extract displays characteristic peaks for peptides, polysaccharides, and acyl lipids (Results).

As the macroscopic bubbles in natural waters, loosely coated with surfactants, slowly shrink in size to become film-stabilized gas microbubbles $(5,23)$, the oxygen group-metal interactions are probably replaced by hydrogen bonding between the various oxygen-containing functional groups of the surfactants in the insoluble monolayer. This transition appears likely since the biochemical findings (see below) indicate that the microbubble surfactant mixture actually represents a glycopeptidelipopolysaccharide complex.

The surfactant complex appears to be reversibly held together partly by hydrogen bonding, since either electrophoresis in $8 M$ urea-polyacrylamide gels or gel-filtration column chromatography (on Sephadex G-25) in eluting buffer containing $4 \mathrm{M}$ guanidine- $\mathrm{HCl}$ was previously found (5) to be sufficient to monitor the behavior of the monomeric form of the glycopeptide fraction. Such hydrogen bonding between protein and carbohydrate in monomolecular films at an air/water interface has been described by others earlier $(24,25)$. Nonpolar penetration also appears likely to be involved in formation of the microbubble surfactant complex since nonpolar side chains of the glycopeptides can penetrate into the lipophilic portion of the lipopolysaccharide material. Evidence for such reversible, nonpolar interactions is provided by the fact that, both in this study and the previous biochemical study (5), either molecular filtration (through a 5000-Da cutoff membrane filter) of the ethanol-solubilized microbubble surfactant or gel-filtration column chromatography (on Sephadex LH-20) in a 95\% ethanol/ $5 \%$ water eluting solvent mixture also has been found sufficient to monitor the behavior of glycopeptide monomers.

The polysaccharide:glycopeptide weight ratio within the surfactant complex, as estimated from the chemical analyses of peak II (Results), was found to be quite high, i.e., 40:1. Interestingly, this considerable ratio is still not sufficient to explain quantitatively the large areas encountered with the surface pressureversus-area curves recently obtained for spread monolayers of the microbubble surfactant mixture at an air/water interface (11). Ac- 
cordingly, additional (nondestructive) measurements involving NMR spectroscopy on aliquots from peak II (and peak I) beforehand revealed the presence of a very significant quantity of lipid remaining in this further purified, microbubble surfactant mixture as well (Rice and D'Arrigo, unpublished data).

Despite the relatively small weight contribution of the glycopeptide fraction to the microbubble surfactant complex, this fraction has continually been found (5) to represent a reliable and characteristic component of microbubble surfactant preparations isolated from both marine algae and forest soils. The amino acid molar ratios shown in Table II (for peaks I and III) resemble those obtained with less pure preparations (5) of the glycopeptide fraction, although the agreement among individual amino acid determinations is understandably far better in the present study. The agreement is particularly striking in the case of the main glycopeptide subfraction (peak I in Table II), which may indicate the existence of a single type of protein precursor. An earlier search of the biochemical literature (5) suggested several animal sources for the protein precursor. (See also the related work of Loeb and Neihof (26) on marine conditioning films.) The literature search was now expanded and yielded the conclusion that another possible and more widespread precursor is the light-harvesting chlorophyll $a / b$-protein (LHCP), which is present in almost all photosynthetically grown higher plants and green algae (27-29). It is by far the major pigmentprotein in these plants and accounts for 40$60 \%$ of the total chlorophyll $(27,28)$. Table III lists the amino acid molar ratios determined for LHCP from several plant sources, and compares these results with the mean values obtained for the main glycopeptide subfraction (peak I in Table II) from microbubble surfactant. It can be seen from Table III that the amino acid composition of LHCP clearly resembles that of the main glycopeptide subfraction. Specifically, in both cases nonpolar residues represent a majority and near constant fraction (i.e., 59-62\%) of the amino acid composition, with the relative amounts of such residues in practically all individual cases listed following the pattern: glycine $>$ leucine, alanine, valine, proline $>$ isoleucine, phenylalanine $>$ methionine, tryptophan (Table III). Accordingly, the glycopeptide fraction of microbubble surfactant may represent a degradation product of the light-harvesting chlorophyll $a / b$-protein, which is well known (27-29) to be extremely widely distributed in terrestrial, fresh-water, and saltwater environments.

\section{REFERENCES}

1. Christman, R. F., and Ghassemi, M., J. Amer. Water Works Assoc. 55, 723 (1966).

2. D'Arrigo, J. S., J. Chem. Phys. 75, 962 (1981),

3. D'Arrigo, J. S., J. Chem. Phys. 71, 1809 (1979).

4. D'Arrigo, J. S., J. Chem. Phys. 72, 5133 (1980).

5. D'Arrigo, J. S., Advan. Colloid Interface Sci. 19, 253 (1983).

6. D'Arrigo, J. S., in "Microbial-Enhanced Oil Recovery" (J. E. Zajic, Ed.). PennWell Press, Tulsa, 1983.

7. "Hawaii Soil Survey." University of Hawaii, Honolulu, 1972.

8. Haider, K., Nagar, B. R., Saiz-Jimenez, C., Meuzelaar, H. L. C., and Martin, J. P., in "Soil Organic Matter Studies," Vol. II, p. 213. IAEA, Vienna, 1977.

9. Saiz-Jimenez, C., Haider, K., and Meuzelaar, H. L. C., Geoderma 22, 25 (1979).

10. Haverkamp, J., Meuzelaar, H. L. C., Beuvery, E. C., Boonekamp, P. M., and Tiesjema, R. H., Anal. Biochem. 104, 407 (1980).

11. D'Arrigo, J. S., J. Colloid Interface Sci. 100, 106 (1984).

12. Neuberger, A., and Marshall, R. D., in "Glycoproteins: Their Composition, Structure, and Function" (A. Gottschalk, Ed.), p. 190. Elsevier, Amsterdam, 1966.

13. Martin, F., and Saiz-Jimenez, C., Z. Pflanzenernaer. Bodenkd 135, 58 (1973).

14. Schnitzer, M., in "Soil Organic Matter" (M. Schnitzer and S. U. Khan, eds.), p. 1. Elsevier, Amsterdam, 1978.

15. Dormaar, J. F., Canad. J. Soil Sci. 58, 135 (1978).

16. Meuzelaar, H. L. C., Kistemaker, P. G., and Posthumus, M. A., Biomed. Mass Spectrom. 1, 312 (1974).

17. Martin, F., Saiz-Jimenez, C., and Cert, A., Soil Sci. Soc. Amer. J. 43, 309 (1979). 
18. Anonymous, "Sephadex LH-20 Chromatography in Organic Solvents." Pharmacia, Uppsala, 1978.

19. Vedy, J. C., and Bruckert, S., Pedologie 20, 135 (1970).

20. Dawson, H. J., Ugolini, F. C., Hrutfiord, B. F., and Zackara, J., Soil Sci. 126, 290 (1978).

21. Khan, S. U., Soil Sci. 109, 227 (1970).

22. Candler, R., and van Cleve, K., Soil Sci. 134, 176 (1982).

23. Johnson, B. D.; and Cooke, R. C., Science 213, 209 (1981).

24. MacRitchie, F., and Alexander, A. E., J. Colloid Sci. 16, 57 (1961).

25. MacRitchie, F., and Alexander, A. E., J. Colloid Sci. 16, 61 (1961).

26. Loeb, G. I., and Neihof, R. A., Advan. Chem. 145, 319 (1975).
27. Thornber, J. P., Annu. Rev. Plant Physiol. 26, 127 (1975).

28. Thornber, J. P., and Barber, J., in "Photosynthesis in Relation to Model Systems" (J. Barber, Ed.), p. 27. Elsevier, Amsterdam, 1979.

29. Hiller, R. G., and Goodchild, D. J., in "The Biochemistry of Plants: A Comprehensive Treatise. Vol. 8. Photosynthesis" (M. D. Hatch and N. K. Boardman, Eds.), p. 1. Academic Press, New York, 1981.

30. Thornber, J. P., Stewart, J. C., Hatton, M. W. C., and Bailey, J. L., Biochemistry 6, 2006 (1967).

31. Ryrie, I. J., and Fuad, N., Arch. Biochem. Biophys. 214, 475 (1982).

32. Kan, K. S., and Thornber, J. P., Plant Physiol. 57, 47 (1976). 